Article

\title{
Hybrid Pulse Width Modulation Strategy of a High-Frequency Link Three-Phase Four-Leg Matrix Converter Based on Compensation Theory
}

\author{
Rutian Wang * ${ }^{\mathbb{D}}$, Fuxu Wang, Haining Pan and Sutong Liu \\ Key Laboratory of Modern Power System Simulation and Control \& Renewable Energy Technology, \\ Ministry of Education (Northeast Electric Power University), Jilin 132012, China; wfx190510@163.com (F.W.); \\ panhaining@126.com (H.P.); 2201700145@neepu.edu.cn (S.L.) \\ * Correspondence: wrtmail@163.com; Tel.: +86-159-4869-6698
}

Received: 10 November 2019; Accepted: 17 December 2019; Published: 19 December 2019

\begin{abstract}
A high-frequency link (HFL) three-phase four-leg matrix converter (MC) can output three-phase balanced voltage for unbalanced load conditions. It is an inverter with great development potential. This paper presents a hybrid pulse width modulation (HPWM) strategy for a four-wire matrix converter based on the fourth bridge leg compensation method. Firstly, the rear-stage topology of a high-frequency link three-phase four-leg matrix converter is decoupled into two sets of ordinary three-phase four-wire inverters. Then the compensation strategy is applied to separate the fourth bridge leg from the coupling of the ordinary inverter and realize its independent control. Under the theory of compensation, the fourth bridge leg plays a role in compensating the deviation of the neutral point potential when the load is unbalanced, the fourth bridge leg does not need to work when the load is balanced. Finally, the fourth bridge leg modulation wave obtained by the compensation method is combined with the front three bridge leg modulation waves to perform the coupling control using the hybrid pulse width modulation strategy. It has changed the problem that the previous hybrid pulse width modulation strategy cannot be directly applied to the four-wire matrix converter. This strategy is simple to control, without adding any auxiliary commutation detection circuitry, can effectively solve the inherent commutation problem in the bidirectional switch tube of the four-wire matrix converter. It simplifies the complexity of the system, reduced control cost, and high switching loss caused by high switching frequency. The fast adjustment function of compensation strategy makes the dynamic response performance of system under load fluctuation state more prominent, the harmonic distortion rate is smaller. The perfect combination of two strategies allows the high-frequency link three-phase four-leg matrix converter with any form of load to give full play to its structural advantages. The related work verifies the feasibility and effectiveness of the modulation method and control logic.
\end{abstract}

Keywords: HFLMC; decoupling and coupling; compensation method; fourth bridge leg control; HPWM

\section{Introduction}

With the development of modern science and technology, the forms of load are becoming more diverse, and the application of various unbalanced loads in power electronics technology is also universal. The use of these unbalanced loads of electrical equipment will lead to the unbalance of our power supply system and affect the quality of power supply in the power grid. At the same time, the fluctuation of the load will increase the harmonic distortion of output voltage, and even cause the voltage of the grid to rise or fall, causing oscillations, which will affect the safety of power operation, 
and various devices have higher and higher requirements for quality of power system input $[1,2]$. The contradiction between these two aspects has become remarkable. Thus, it is necessary to study the control of three-phase inverter under unbalanced grid conditions.

In actual situations, the inverter is often required to have the ability to supply power to unbalanced load. For the three-phase three-wire inverter topology, when the three-phase load imbalance occurs, the phase current also becomes unbalanced, resulting in a deviation of the neutral point potential of the load, output three-phase unbalanced hazardous voltage, thereby affecting the normal operation of the power grid. This is not overcome by the three-leg inverter's own topology. The three-phase four-leg inverter is widely studied in recent years. It uses three-phase four-wire power supply topology. Compared with ordinary three-phase three-leg inverters, it has one more output bridge leg phase N, which can connect to the load neutral point to control the load neutral point potential, so that the three-phase symmetrical balanced voltage can be output under unbalanced load conditions [3-6].

In order to protect the safety of the equipment and human body, the inverter needs to be electrically isolated from the input side and output side. However, the ordinary inverter topology itself does not have the function of isolating electrical. It is necessary to add a frequency transformer between the inverter and load. This will increase the volume and weight of the transformer, the noise pollution of the transformer is serious, the dynamic response performance of the system is poor when load fluctuates $[7,8]$.

The high-frequency link (HFL) three-phase four-leg matrix converter (MC) is a new type of inverter topology developed on the basis of ordinary three-phase four-leg inverter. It can satisfy the increasing demand of high power density and does not affect the performance and reliability of the inverter. In the topology, a high-frequency isolation transformer is used to transfer energy, so that it not only has the function of electrical isolation, but also reduces the volume and mass of the system through the frequency rise of the transformer. At the same time, it inherits the advantages of the MC, such as sinusoidal input, bidirectional energy flow, adjustable power factor, and no need for a large capacity energy storage element [9-11]. For the HFL three-phase four-leg MC, Yan proposed a closed-loop control strategy based on the symmetrical component method [12]. The four bridge leg of the MC is controlled as a whole, which leads to large switching losses. When the load fluctuates, the dynamic response performance is insensitive, and the harmonic distortion is large. A mathematically cumbersome coordinate transformation is required, which increases the complexity and difficulty of implementation. An HFL three-phase four-leg MC modulation strategy with a separate control of the front three bridge leg and fourth bridge leg is adopted to improve the utilization efficiency of the switch [13]. However, in order to obtain good anti-interference and followability, additional adjustment systems are needed to reduce control errors. This not only increases the cost of the system, but also its practicality is limited by the adjustment accuracy. Aijuan adopted a three-dimensional space vector PWM (3D-SVPWM) control strategy to maintain low harmonic distortion of the output voltage under a variable unbalanced load [14]. However, the concept of three-dimensional space vector is introduced into this method, which is more complex in both control and implementation method. In the development of the power industry, cost control has always been a key factor restricting innovative reform. The above four-wire $\mathrm{MC}$ control strategy generally requires a commutation detection circuit, which increases the cost. In addition, in order to obtain high quality output waveform with low harmonic distortion and reduce high switching losses caused by the high switching frequency. Soft switching is an option to reduce switching losses [15]. However, the soft switching method is limited by the duty cycle and load type. An ideal alternative is hybrid pulse width modulation (HPWM) with no significant switching losses to achieve high quality output waveforms [16].

This paper proposes a four-wire hybrid pulse width modulation strategy that does not require a commutation detection circuit for the HFL $3 \times 4 \mathrm{MC}$ topology. The compensation strategy is adopted to realize the separation of the fourth bridge leg from coupling of the front three bridge leg, so as to achieve independent control of the fourth bridge leg. Under the balanced load condition the compensation for the neutral potential deviation is zero, the modulation wave of the fourth bridge 
leg does not exist, and only the front three bridge leg operates. When the load is unbalanced, the fourth bridge leg can immediately compensate the neutral point potential deviation caused by the unbalanced load, the front three and the fourth bridge leg jointly control the voltage output. This method enhances the compatibility of $3 \times 3 \mathrm{MC}$ and $3 \times 4 \mathrm{MC}$ control, makes rational used of power switch and reduces the cost increase caused by switch loss. After applying the compensation method, the fourth bridge leg modulation wave is obtained. At this time, the advantages of the HPWM strategy under the three-wire MC can be completely applied to the four-wire MC. The method is simple in control, the safe commutation problem of the bidirectional switch tube in the four-wire MC topology can be effectively solved without adding any auxiliary commutation detection circuit. It simplifies the complexity of the system and achieves real low cost and high performance.

On the control function, the application of the compensation strategy also speeds up the adjustment of the system under load fluctuations, improve the dynamic response performance, reduce the harmonic distortion rate, and greatly improve the capacity of power grid with unbalanced load. In terms of safety, in addition to the realization of safe commutation, the high-frequency transformer structure in the topology not only has the function of changing the range of the output voltage, but also solves the electrical isolation between the input and output side so that the inverter and personal safety are guaranteed [17,18]. In terms of topology, it also has excellent control performance, and has a compact and reliable structure [19]. Therefore, the proposed strategy makes the HFL three-phase four-leg MC have a good prospect in practicality.

\section{The Topology of HFL Three-Phase Four-Leg MC}

The HFL three-phase four-leg MC adopts the three-phase four-wire power supply topology which shown in Figure 1. The main circuit adopts DC/AC1/AC2 two stage power conversion mode, defining the pre-stage and rear-stage of the HFL $3 \times 4 \mathrm{MC}$ circuit with a high frequency transformer in the middle of the topology. The pre-stage DC/HFAC high-frequency square wave inverter is composed of a single phase full bridge inverter circuit and a high-frequency transformer, output a high frequency alternating current square wave $\mathrm{AC} 1$ to achieve a first stage power conversion; a three-phase four-leg matrix converter and a filter inductor $L$ and a filter capacitor $C$ are used to constitute a rear-stage HFAC/LFAC matrix conversion circuit, which converts the high-frequency alternating square wave $\mathrm{AC} 1$ into a power frequency sinusoidal wave AC2 to realize the second stage power conversion [20]. The switches used in the rear-stage MC topology are bidirectional switching tubes composed of two IGBTs. $u_{\mathrm{a}}, u_{\mathrm{b}}, u_{\mathrm{c}}$, and $u_{\mathrm{n}}$ are the bridge leg terminal voltages, $i_{\mathrm{a}}, i_{\mathrm{b}}, i_{\mathrm{c}}$, and $i_{\mathrm{n}}$ are the filter inductor currents, $u_{\mathrm{AO}}, u_{\mathrm{BO}}$, and $u_{\mathrm{CO}}$ are the three-phase output voltages of the matrix converter.

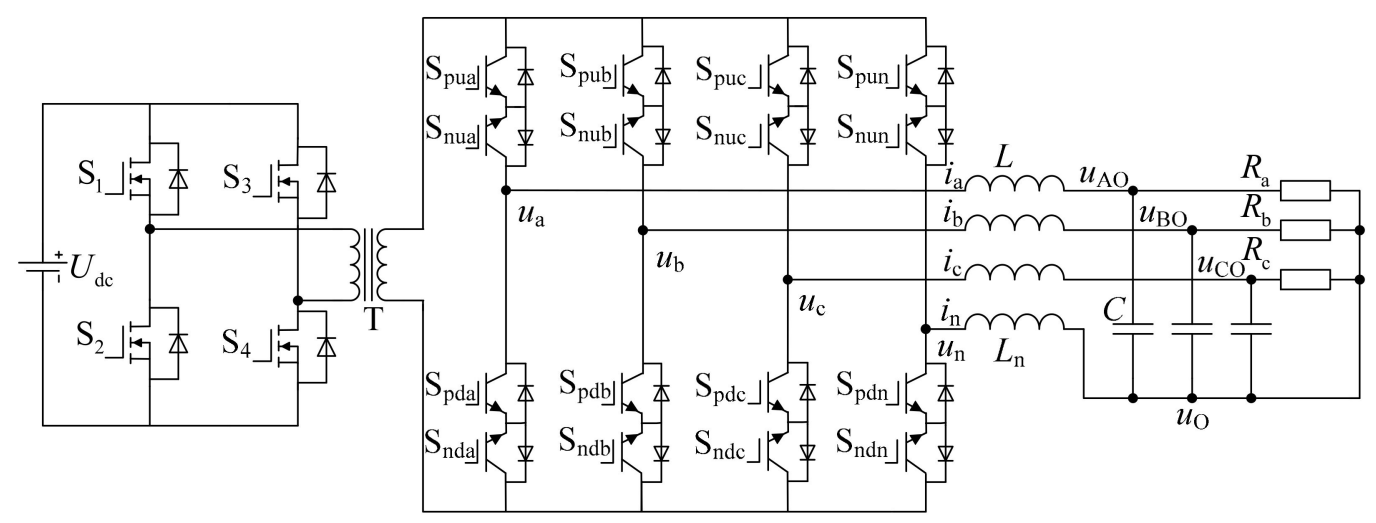

Figure 1. Topology of high-frequency link (HFL) three-phase four-leg matrix converter (MC). 


\section{Control Strategy of HFL Three-Phase Four-Leg MC}

\subsection{The Compatibility Control Idea of $3 \times 3 \mathrm{MC}$ and $3 \times 4 M C$}

The load in power electronics will be affected by external factors, from balanced to unbalanced load, also from unbalanced to balanced load, and there will be constant switching between balanced and unbalanced state. With the continuous switching of load state, it will inevitably affect the working performance of the inverter, so that the output voltage imbalance and total harmonic distortion rate of the system will continue to increase, finally affecting the power supply quality of the power grid [21]. If the load is balanced, the three-phase three-wire MC can satisfy the requirements of the power supply. If the load is unbalanced, the three-phase four-wire MC can satisfy the requirements of the power supply.

Therefore, we adopt the compatible control idea from HFL $3 \times 3 \mathrm{MC}$ to HFL $3 \times 4 \mathrm{MC}$, so that its topology can choose the specific work topology form according to the change of load. When the load is balanced, the fourth bridge leg does not work, only the front three bridge leg work, playing the role of $3 \times 3 \mathrm{MC}$ topology. When the load is no longer balanced, the four bridge leg work together to function as a $3 \times 4 \mathrm{MC}$. It can be seen from the above that the fourth bridge leg needs to be controlled by maneuvering, so we must find a strategy to satisfy this idea. As shown in Figure 2, a compensation method is adopted for the "N-phase bridge leg", the four bridge leg control function is separated, and the $\mathrm{N}$-phase bridge leg is independently controlled. This method can extend the modulation strategy of $3 \times 3 \mathrm{MC}$ to $3 \times 4 \mathrm{MC}$, so that the HFL three-phase four-leg MC can be fully compatible for different load conditions and has good adaptability.

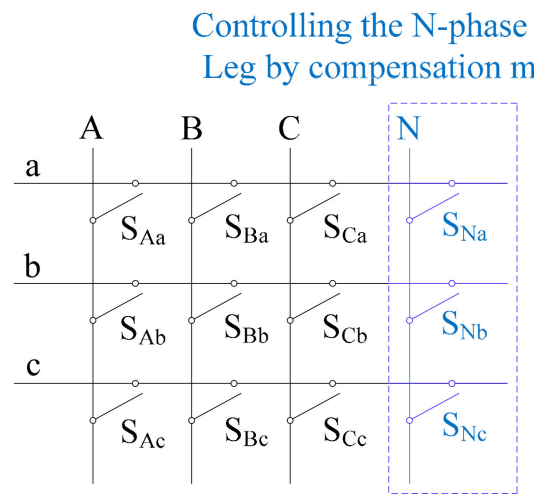

$3 \times 4 \mathrm{MC}$

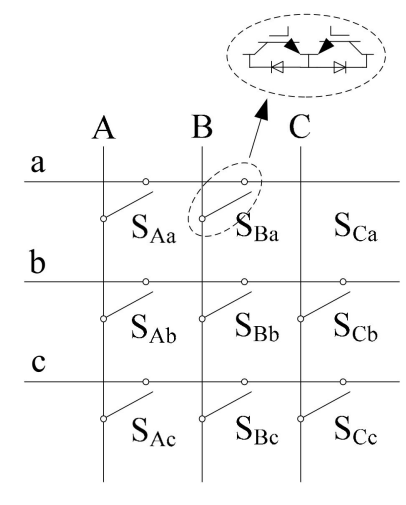

$3 \times 3 \mathrm{MC}$

Figure 2. Compatible control idea of a $3 \times 3 \mathrm{MC}$ and $3 \times 4 \mathrm{MC}$.

\subsection{Decouple Control of HFL Three-Phase Four-Leg MC}

According to the characteristics of topology of HFL three-phase four leg MC, we apply a decoupling control strategy to convert the MC into ordinary inverter control problems. This can reduce the difficulty of analyzing the MC and make the modulation process easy to implement [22]. As shown in Figure 3, when the pre-stage output is a positive square wave, the rear-stage inverter is defined as positive group inverter. On the contrary, the rear-stage inverter is defined as a negative group inverter.

According to the compatible control idea and decoupling modulation strategy, after topology decoupling, the control of the HFL three-phase four-leg MC is firstly designed according to the independent control of the N-phase bridge leg. Then, the front three bridge leg and N-phase bridge leg are controlled by the HPWM modulation strategy based on the compensation method. In other words, it is the process of synthesizing the drive signal of the switch in the topology through the coupling logic. 


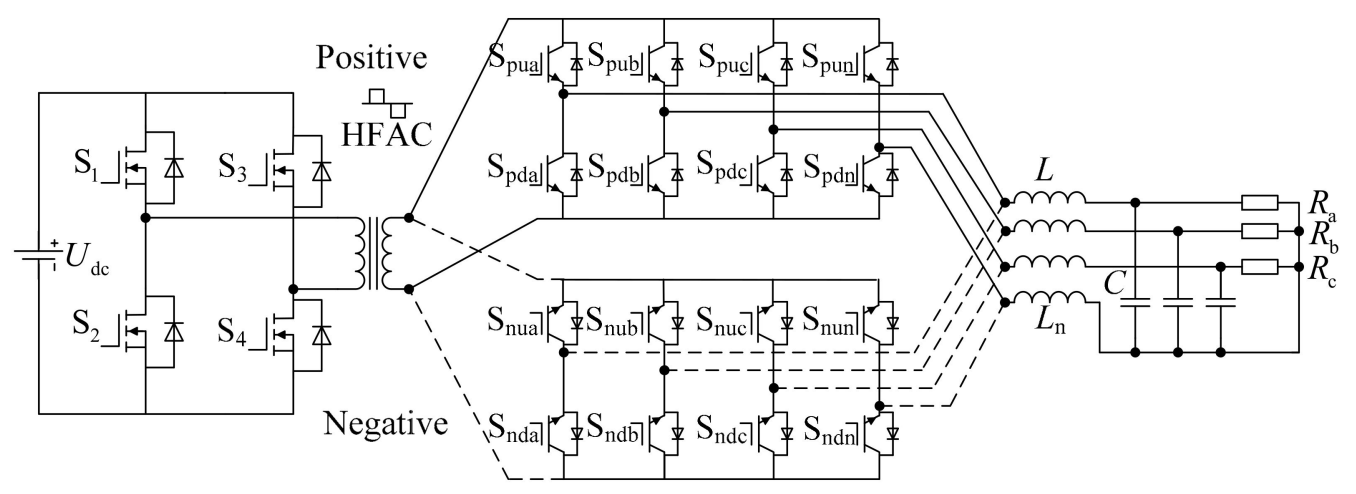

Figure 3. The decoupled topology of HFL three-phase four-leg MC.

\subsection{The Compensation Strategy of the N-Phase Bridge Leg}

According to the decoupling diagram of Figure 3, Figure 4 shows the topology of an ordinary three-phase four-leg inverter after decoupled a HFL three-phase four-leg MC.

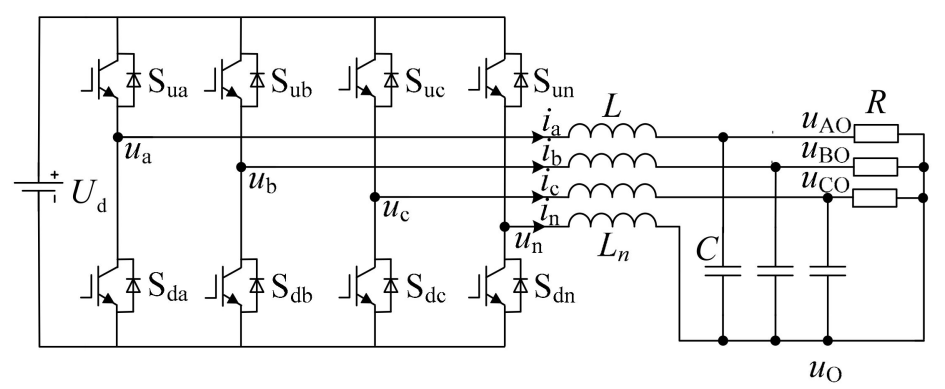

Figure 4. Ordinary three-phase four-leg inverter.

With respect to the fourth bridge leg of the ordinary three-phase four-leg inverter, the essence of its control is not to obtain the mathematical decoupling through complex coordinate transformation, but to separate the fourth bridge leg from the coupling control of other bridge legs. This paper uses a compensation control scheme. This solution can not only separate the fourth bridge leg control from the coupling with other bridge legs, and the fourth bridge leg structure can also completely compensate for the effects of load imbalance or nonlinearity, which gives full play to the advantages of the four-leg structure to achieve effective control of the inverters.

According to the topology of the three-phase four-leg inverter, the terminal voltage of the front three bridge leg is set as follows:

$$
\left\{\begin{array}{c}
u_{\mathrm{a}}=\mathrm{M}_{1}(t) \sin (\omega t-\theta) \\
u_{\mathrm{b}}=\mathrm{M}_{2}(t) \sin (\omega t-2 \pi / 3-\theta) \\
u_{\mathrm{c}}=\mathrm{M}_{3}(t) \sin (\omega t-4 \pi / 3-\theta)
\end{array}\right.
$$

If control $u_{\mathrm{a}}, u_{\mathrm{b}}, u_{\mathrm{c}}$, and $u_{\mathrm{n}}$ to make the voltage output from the inverter three-phase symmetrical, and it can satisfy zero sum of front three bridge leg terminal voltage. Then the influence of load unbalance or non-linearity can be completely eliminated by controlling the voltage $u_{\mathrm{n}}$ of the fourth bridge leg.

According to Kirchhoff's law of voltage and current, the equation for the three-phase four-leg inverter can be obtained:

$$
\left\{\begin{array}{c}
u_{\mathrm{a}}=L \mathrm{~d} i_{\mathrm{a}} / \mathrm{d} t+u_{\mathrm{AO}}+u_{\mathrm{O}} \\
u_{\mathrm{b}}=L \mathrm{~d} i_{\mathrm{b}} / \mathrm{d} t+u_{\mathrm{BO}}+u_{\mathrm{O}} \\
u_{\mathrm{c}}=L \mathrm{~d} i_{\mathrm{c}} / \mathrm{d} t+u_{\mathrm{CO}}+u_{\mathrm{O}} \\
u_{\mathrm{n}}=u_{\mathrm{O}}-L_{\mathrm{n}} \mathrm{d} i_{\mathrm{n}} / \mathrm{d} t
\end{array}\right.
$$


Then:

$$
u_{\mathrm{a}}+u_{\mathrm{b}}+u_{\mathrm{c}}=L \mathrm{~d} i_{\mathrm{n}} / \mathrm{d} t+\left(u_{\mathrm{AO}}+u_{\mathrm{BO}}+u_{\mathrm{CO}}\right)+3\left(u_{\mathrm{n}}+L_{\mathrm{n}} \mathrm{d} i_{\mathrm{n}} / \mathrm{d} t\right)
$$

In order to realize that the fourth bridge leg voltage can completely compensate the voltage drop caused by inductance. Therefore in the steady state, the voltage of the fourth bridge leg not only compensates the voltage drop of the neutral line inductance, but also compensates the voltage drop of the three-phase inductance, make $L=L_{\mathrm{n}}$. For the given input in Equation (1), when $\mathrm{M}_{1}(t)=\mathrm{M}_{2}(t)=$ $\mathrm{M}_{3}(t)$, we can get $u_{\mathrm{a}}+u_{\mathrm{b}}+u_{\mathrm{c}}=0$, At this time, the following can be introduced by the Equation (3):

$$
\left(u_{\mathrm{AO}}+u_{\mathrm{BO}}+u_{\mathrm{CO}}\right)+4 L_{\mathrm{n}} \mathrm{d} i_{\mathrm{n}} / \mathrm{d} t+3 u_{\mathrm{n}}=0
$$

If the fourth bridge leg control voltage $u_{\mathrm{n}}$ is designed as:

$$
u_{\mathrm{n}}=-\frac{4}{3} L_{\mathrm{n}} \frac{\mathrm{d} i_{\mathrm{n}}}{\mathrm{d} t}
$$

The following can be introduced:

$$
u_{\mathrm{AO}}+u_{\mathrm{BO}}+u_{\mathrm{CO}}=0
$$

According to Equation (6), the output three-phase voltage symmetry can be obtained.

Equation (5) shows the differential calculation of the current $i_{\mathrm{n}}$ contained in the modulated wave of the fourth bridge leg, which is not feasible in practical application system, because in the actual working conditions, the differential calculation will amplify the disturbance caused by the switching action, which will easily cause instability of the system and poor quality of the output electrical parameters in the process of regulation. The phase difference between $\mathrm{d} i_{\mathrm{n}} / \mathrm{d} t$ and $\int i_{\mathrm{n}} \mathrm{d} t$ is approximately $180^{\circ}$, and the amplitude ratio relationship is approximately $\omega^{2}$, so the integral can be equivalent to a negative differential in phase so that the integral term can be used instead of the differential term in the adjustment parameter. Therefore, the fourth bridge leg control design can use $(4 / 3) \omega^{2} L \int i_{\mathrm{n}} \mathrm{d} t$ instead of $-(4 / 3) L \mathrm{~d} i_{\mathrm{n}} / \mathrm{d} t$, then in the actual system, the fourth bridge leg controller is:

$$
u_{\mathrm{n}}=\frac{4}{3} \omega^{2} L_{\mathrm{n}} \int i_{\mathrm{n}} \mathrm{d} t
$$

The $k\left(u_{\mathrm{AO}}+u_{\mathrm{BO}}+u_{\mathrm{CO}}\right)$ term is added to the actual control $u_{\mathrm{n}}$ to adjust the three-phase output voltage rapidly. Therefore, the modulation wave of the fourth bridge leg is:

$$
u_{\mathrm{n}}=-\frac{4}{3} L_{\mathrm{n}} \frac{\mathrm{d} i_{\mathrm{n}}}{\mathrm{d} t}+k\left(u_{\mathrm{AO}}+u_{\mathrm{BO}}+u_{\mathrm{CO}}\right)
$$

Due to the excellent control performance of HFL three-phase four-leg MC topology and the rapid regulation of compensation method, this makes the system have less voltage fluctuations and the dynamic response performance well during sudden load change.

\subsection{Hybrid Pulse Width Modulation Control Strategy of HFL Three-Phase Four-Leg MC}

After decoupling, the positive and negative inverters work in coordination according to the HPWM modulation strategy: When the positive inverter works, the eight unidirectional switches of the negative group inverter are all turned on, acting as a freewheeling circuit. On the contrary, the negative group works also has this relationship. Taking the A-phase bridge leg as an example, the control principle of the four-wire MC switch drive signal is given, the logic implementation circuit is designed.

Firstly, the sawtooth wave $u_{\mathrm{ca}}$ and the sinusoidal modulation wave $u_{\mathrm{sa}}$ are compared to obtain two complementary sinusoidal pulse width modulation (SPWM) pulses. Then two high-frequency square waves $u_{1}, u_{2}$ with a duty cycle of 0.5 and complementary are used to logically combine with the 
SPWM pulse. Finally, four switch drive signals on the phase A bridge leg are obtained. The waveform diagram is shown in Figure 5. In the figure, the amplitude of sinusoidal modulation wave $u_{\mathrm{sa}}$ is 1 , the amplitude of sawtooth wave $u_{\mathrm{ca}}$ is $0.8 . u_{1}$ and $u_{2}$ represent the positive and negative high-frequency square waves, respectively. $u_{\text {Skia }}$ represents the four driving signals of the phase A bridge leg.

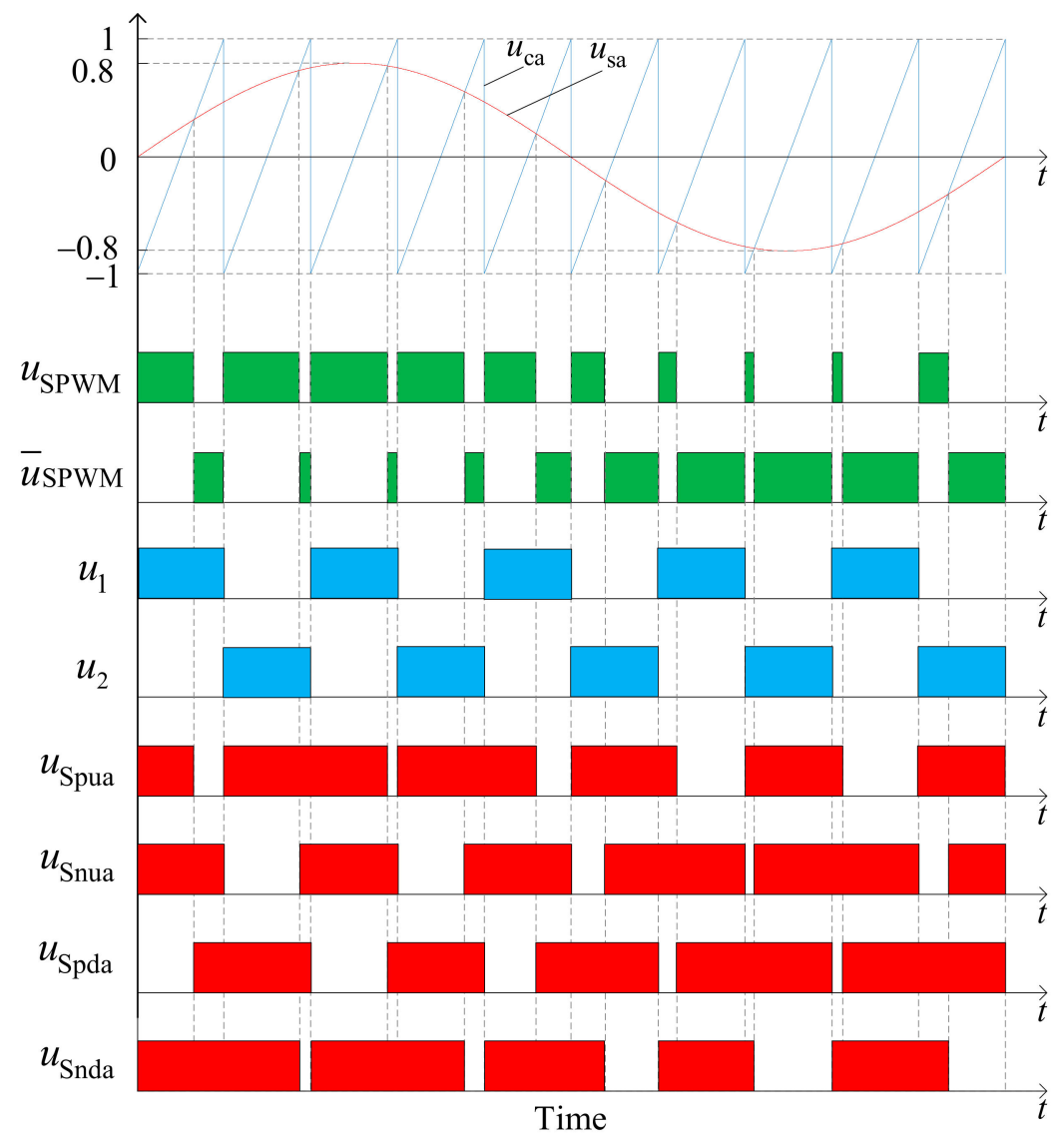

Figure 5. Drive signal for switches of phase A.

Figure 5 shows the control principle waveform of HPWM control based on de-re-couple, and it is easy to understand the control strategy from the figure. Among them, the high-frequency transformer passes a bipolar high-frequency square wave signal, and it can be known that the transformer operating frequency and the switching frequency of high-frequency inverter bridge are still the same, so it can greatly reduce the size of the transformer and output filter links.

$u_{1}, u_{\text {SPWM }}$ is defined as " 1 " with high level and " 0 " with low level using the following switching function:

$$
\left\{\begin{array}{ll}
\mathrm{S}_{k i a}=1 & \mathrm{~S}_{k i \mathrm{a}}: \text { on } \\
\mathrm{S}_{k i \mathrm{a}}=0 & \mathrm{~S}_{k i \mathrm{a}}: \text { off }
\end{array} \quad k \in\{\mathrm{p}, \mathrm{n}\} \quad \mathrm{i} \in\{\mathrm{u}, \mathrm{d}\}\right.
$$

The control logic truth (shown in Table 1) is listed by the above control principle. The definitions of the symbols in Table 1 are shown in Table A1.

Table 1. Truth table of integration SPWM composite.

\begin{tabular}{cccccc}
\hline $\boldsymbol{u}_{\mathbf{1}}$ & $\boldsymbol{u}_{\text {SPWN }}$ & $\boldsymbol{u}_{\text {Spua }}$ & $\boldsymbol{u}_{\text {Snua }}$ & $\boldsymbol{u}_{\text {Spda }}$ & $\boldsymbol{u}_{\text {Snda }}$ \\
\hline 1 & 1 & 1 & 1 & 0 & 1 \\
1 & 0 & 0 & 1 & 1 & 1 \\
0 & 1 & 1 & 0 & 1 & 1 \\
0 & 0 & 1 & 1 & 1 & 0 \\
\hline
\end{tabular}


From Table 1, we can obtain the logic equation of four driving signals of the phase A bridge leg:

$$
\left\{\begin{array}{l}
u_{\text {Spua }}=\overline{u_{1}}+u_{\text {SPWM }} \bullet u_{1} \\
u_{\text {Snua }}=u_{1}+\bar{u}_{\text {SPWM }} \bullet \overline{u_{1}} \\
u_{\text {Spda }}=\overline{u_{1}}+\bar{u}_{\mathrm{SPWM}} \bullet u_{1} \\
u_{\text {Snda }}=u_{1}+u_{\text {SPWM }} \bullet \overline{u_{1}}
\end{array}\right.
$$

In addition, the three-phase high-frequency link matrix converter (HFLMC) is modulated in the control circuit by using an integrated HPWM modulation strategy in which the drive signal of the pre-stage high frequency inverter and the drive signal of the rear-stage MC are combined. Moreover, the HPWM control, itself, has an adaptive one-step commutation, which reduces the commutation difficulty and switching stress, ensuring safe operation of the system [23].

Similarly, the driving signals of the B, C, and N-phase switches can also be obtained, thereby implementing the control of the four bridge leg of rear-stage MC.

\section{Simulation Study}

In order to further verify the feasibility and correctness of the theoretical analysis, in this section, the simulation model of the high-frequency link three-phase four-leg matrix converter is built by using the software of MATLAB/Simulink. The proposed modulation strategy is simulated and verified by changing the load condition of the matrix converter. The simulation parameters are shown in Table 2 . Definitions of abbreviations in Table 2 are shown in Table A2.

Table 2. Simulation parameters.

\begin{tabular}{clc}
\hline Symbol & \multicolumn{1}{c}{ Description } & Value \\
\hline $\mathrm{T}$ & Turn ratio of the high-frequency transformer & $1: 1$ \\
$f_{\mathrm{c}}$ & Carrier frequency & $20 \mathrm{kHz}$ \\
$L$ & Three-phase filter inductor & $0.5 \mathrm{mH}$ \\
$L_{\mathrm{n}}$ & Neutral line inductor & $0.5 \mathrm{mH}$ \\
$C$ & Filter capacitor & $20 \mu \mathrm{F}$ \\
$U_{\mathrm{dc}}$ & Input DC voltage & $200 \mathrm{~V}$ \\
\hline
\end{tabular}

According to Table 2, when the input DC voltage is $200 \mathrm{~V}$, the high frequency transformer coil turns ratio is $1: 1$. The simulation can obtain the high-frequency AC square wave output by the pre-stage inverter, as shown in Figure 6. The waveforms $u_{1}$ and $u_{2}$ in the figure are high-frequency square waves with a duty cycle of 0.5 and complementary, which is consistent with the strategy used in this paper.

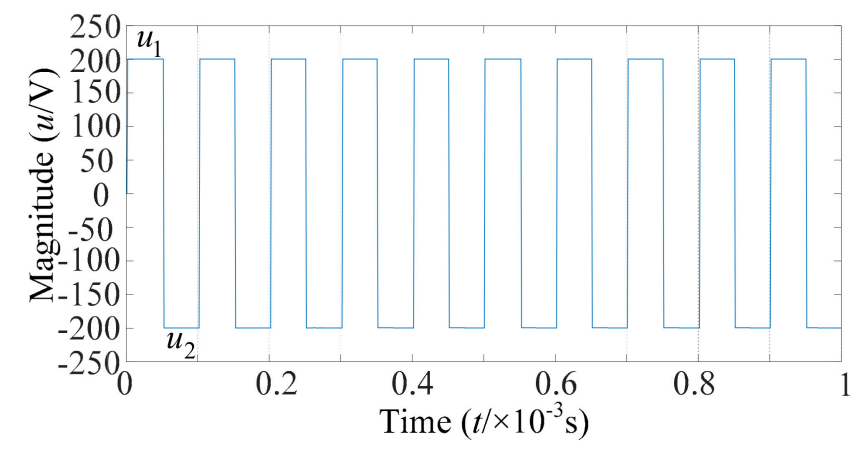

Figure 6. High-frequency alternating current (AC) square wave.

\subsection{Balanced Load}

When we use a high-frequency link three-phase four-leg matrix converter system to control the three-phase balanced load, the load conditions are A, B, and C-phase resistance equals to $15 \Omega$. 
The output three-phase voltage and current waveforms of the inverter are shown in Figure 7a,b. Figure $7 \mathrm{c}$ shows the current waveform of the neutral line. The high current ripple flowing through $U_{\mathrm{dc}}$ is shown in Figure $7 \mathrm{~d}$.

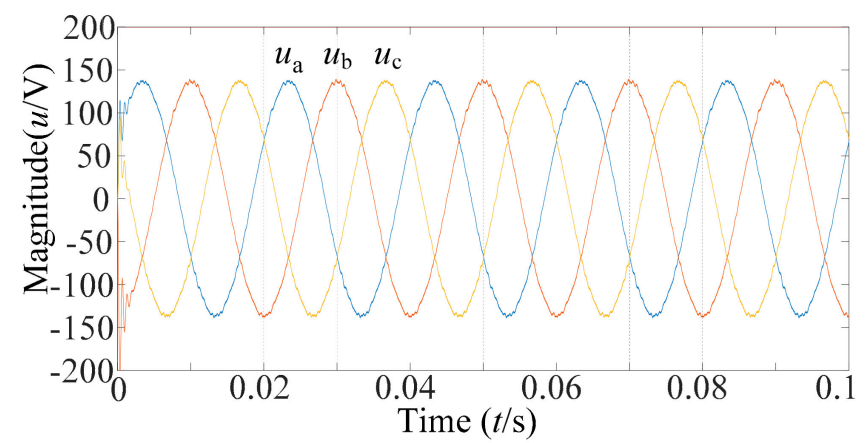

(a)

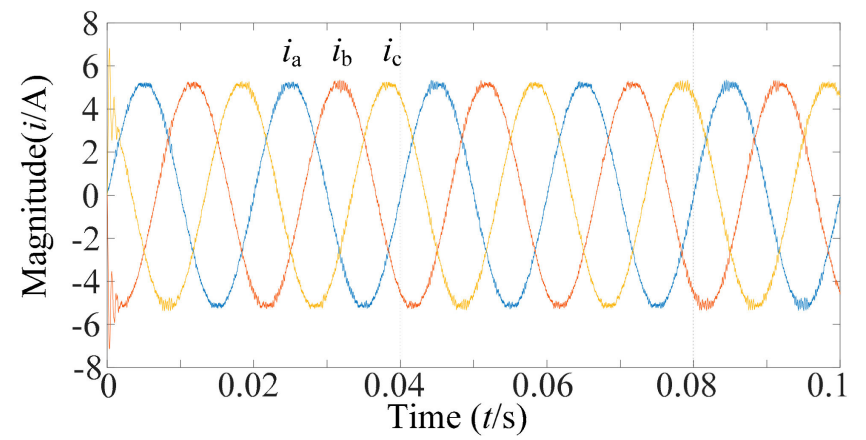

(b)

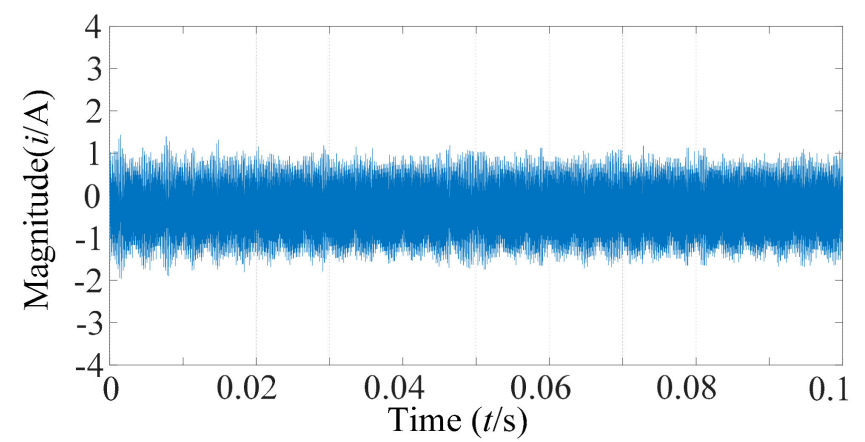

(c)

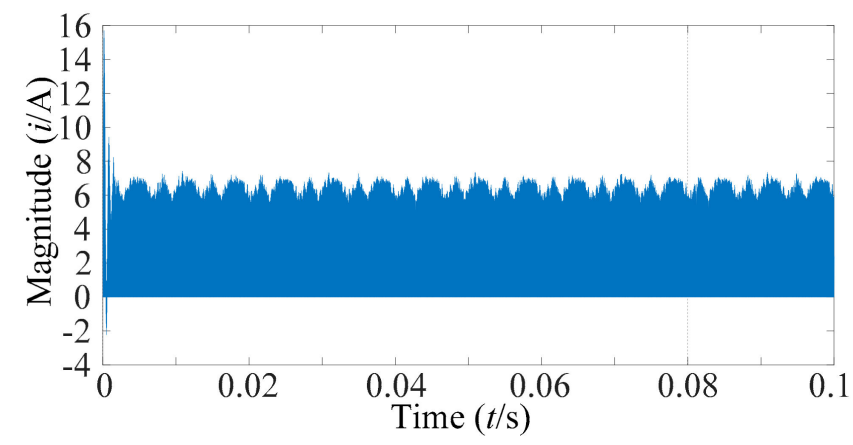

(d)

Figure 7. (a) Three-phase output voltage waveform; (b) three-phase output current waveform; (c) neutral line current waveform; and (d) current waveform flowing through $U_{\mathrm{dc}}$. 
The simulation results show that HFL three-phase four-leg MC can play the role of the $3 \times 3$ inverter, verifying the superiority of the proposed compatible control strategy. The compatibility of the three-phase four-leg inverter to the three-phase three-leg inverter control is improved from the control method, and the versatility of the inverter to balanced and unbalanced conditions is enhanced from the load capacity.

\subsection{Unbalanced Load}

Keep the B-phase and C-phase resistances unchanged at $15 \Omega$, replace the phase A resistor with $50 \Omega$, changing the system with a balanced load to an unbalanced load. Figure $8 \mathrm{a}, \mathrm{b}$ shows the three-phase voltage and current waveform of the high-frequency link three-phase four-leg matrix converter under unbalanced load, respectively. The neutral line current waveform is given in Figure 8c. In order to verify that the proposed modulation strategy can make HFL three-phase four-leg MC transmit sinusoidal voltage to the power grid, the harmonic analysis of the output voltage of the A-phase unbalanced load is shown in Figure $8 \mathrm{~d}$. The $\eta$ THD of A-phase voltage is $0.81 \%$, with almost no low-order harmonic, only the fundamental wave, and its amplitude is 136.8. It can be seen from the waveforms in the figure that the inverter shows good steady-state performance under the unbalanced load. Figure 8e shows the high current ripple flowing through $U_{\mathrm{dc}}$ under unbalanced load.

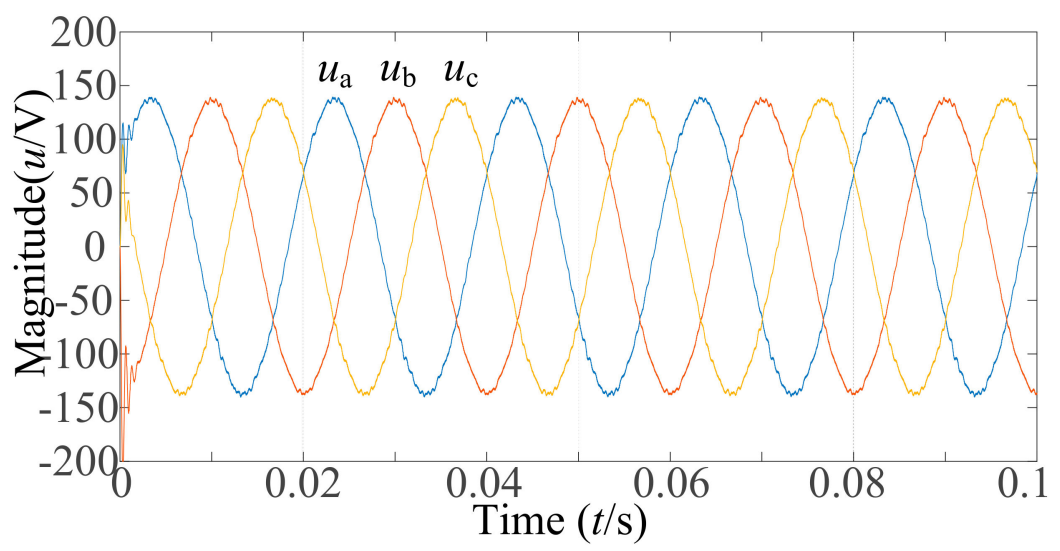

(a)

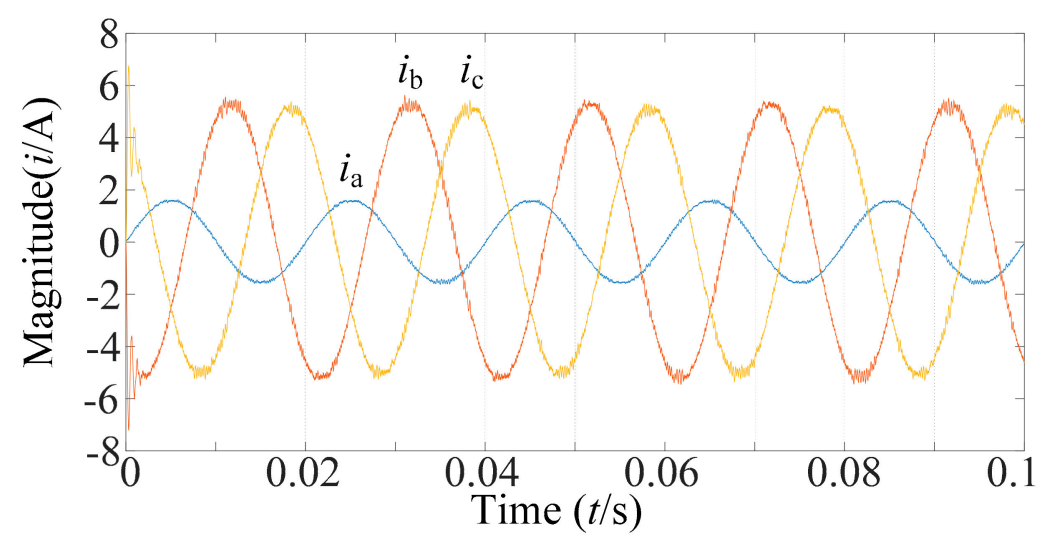

(b)

Figure 8. Cont. 


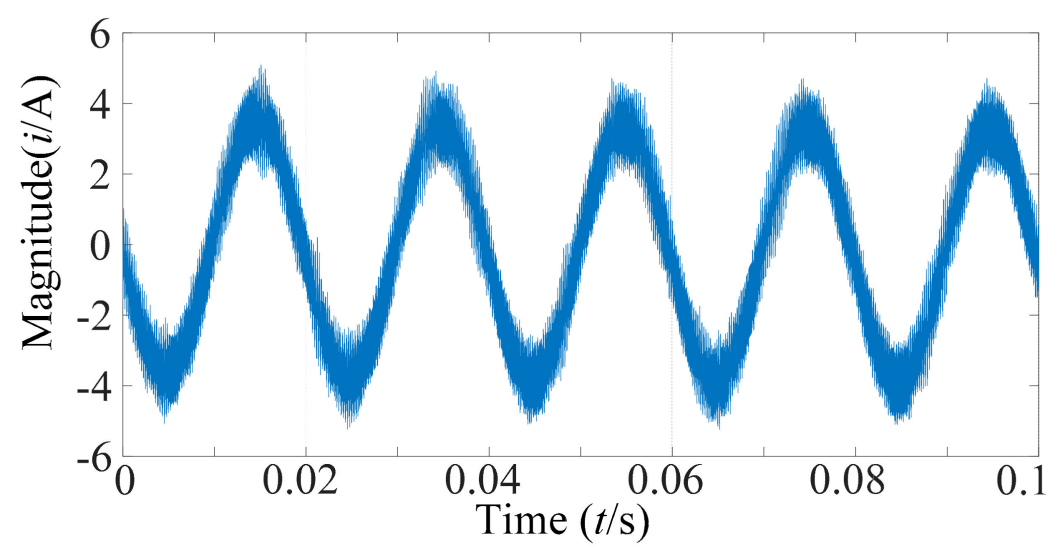

(c)

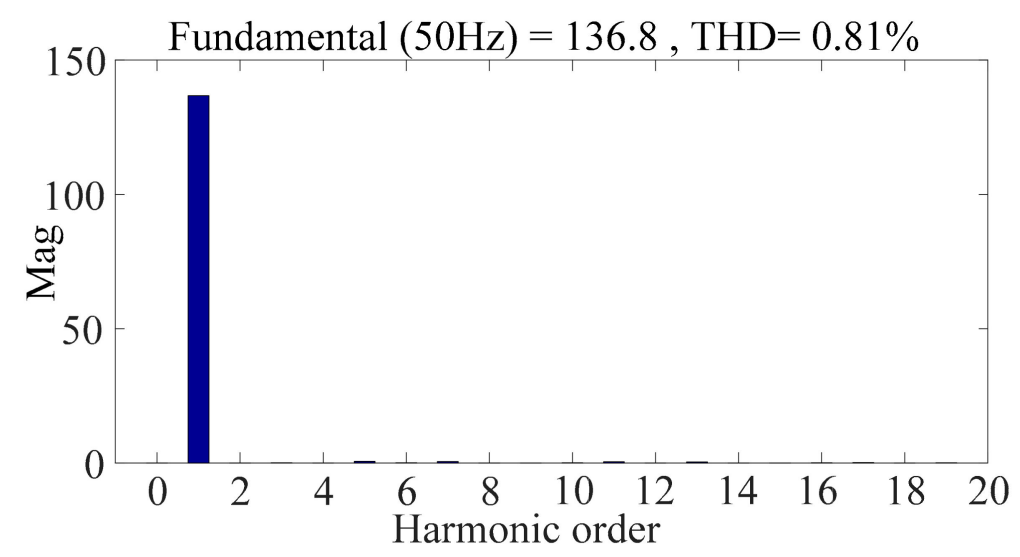

(d)

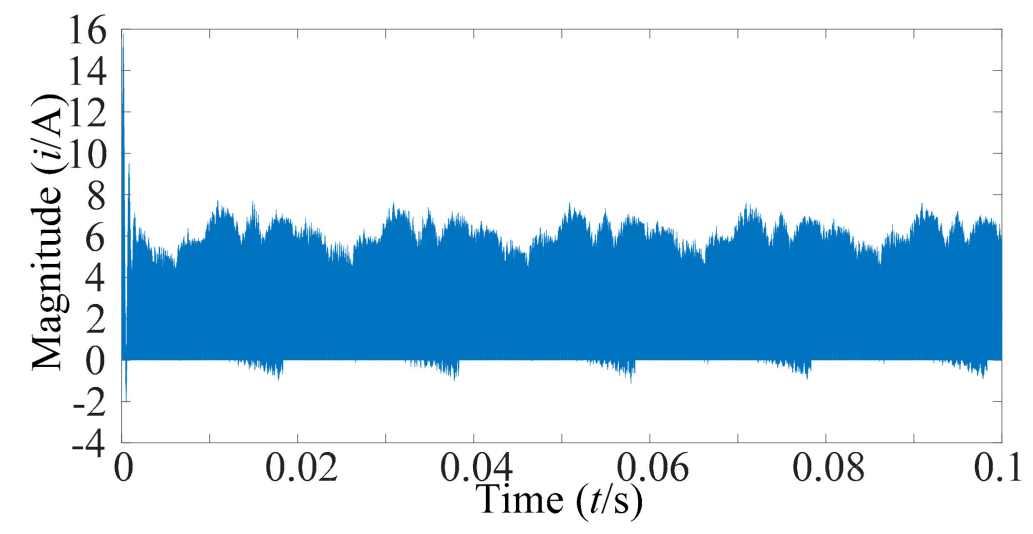

(e)

Figure 8. (a) Three-phase output voltage waveform; (b) three-phase output current waveform; (c) neutral line current waveform; (d) phase A voltage harmonic analysis; and (e) current waveform flowing through $U_{\mathrm{dc}}$.

\subsection{Mutation Load}

In order to investigate the dynamic response speed of the system, the mutation load was simulated. Figure 9 shows the simulation results of the load from the balanced state to unbalanced state. The load conditions are as follows: A-phase resistance is added to $50 \Omega$ from $15 \Omega$ at $0.055 \mathrm{~s}$, Both B-phase and C-phase resistances are $15 \Omega$. Figure 9 a,b show the three-phase output voltage and current waveform, and Figure $9 \mathrm{c}$ shows the neutral line current waveform. It can be seen from the figure that the output 
voltage waveform only shows a slight glitch when the load is abrupt, the time is very short, indicating that the inverter system has a faster response speed. Figure 9d,e shows the A-phase voltage harmonic analysis under load sudden change. There is still almost no low-order harmonic, the amplitude of the fundamental wave at the sudden change point becomes 136.5, and total harmonic distortion is slightly improved. After the mutation point, the total harmonic distortion recovers to $0.80 \%$. The waveform of current flowing through $U_{\mathrm{dc}}$ in the case of a sudden load change is shown in Figure $9 \mathrm{f}$.

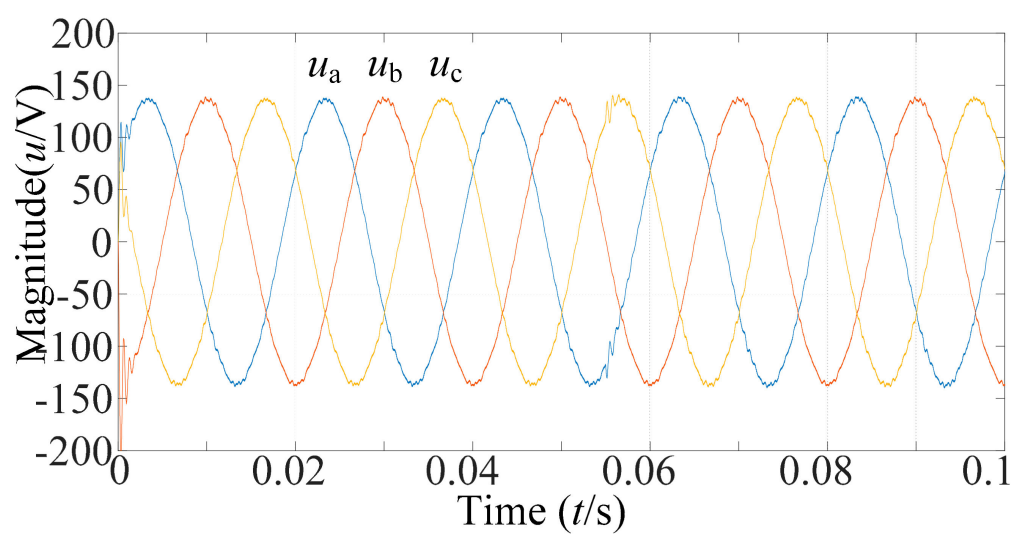

(a)

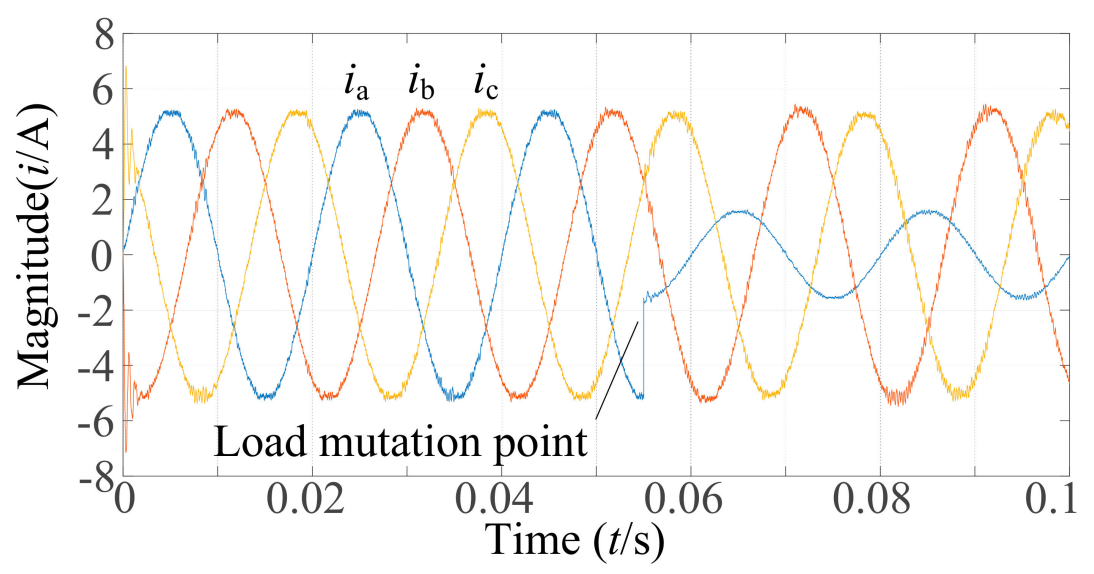

(b)

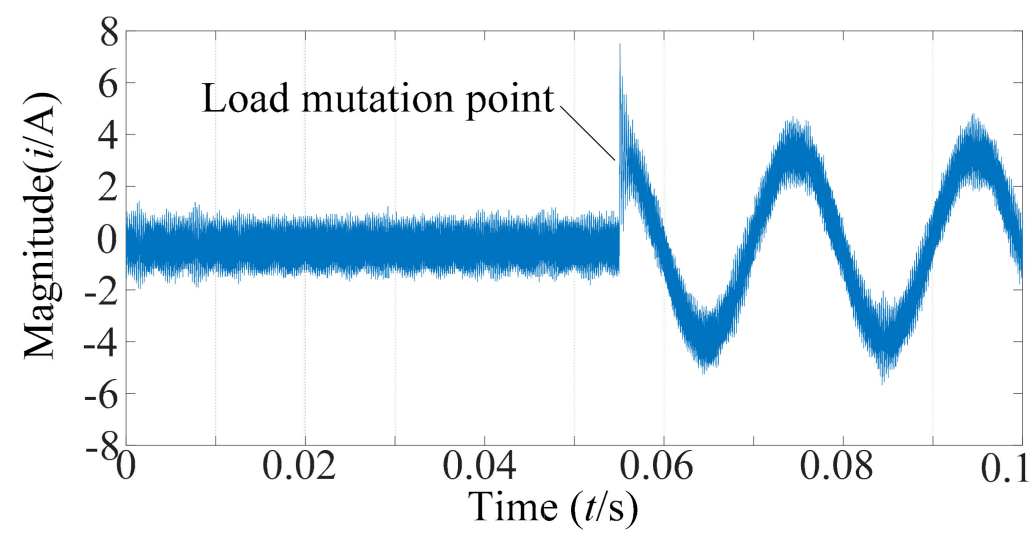

(c)

Figure 9. Cont. 


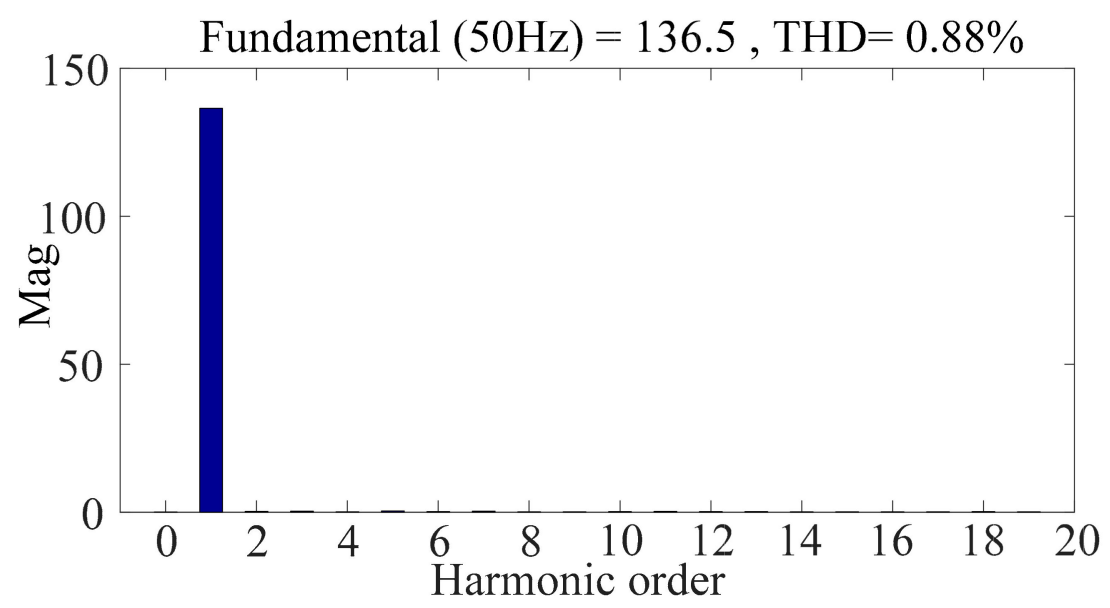

(d)

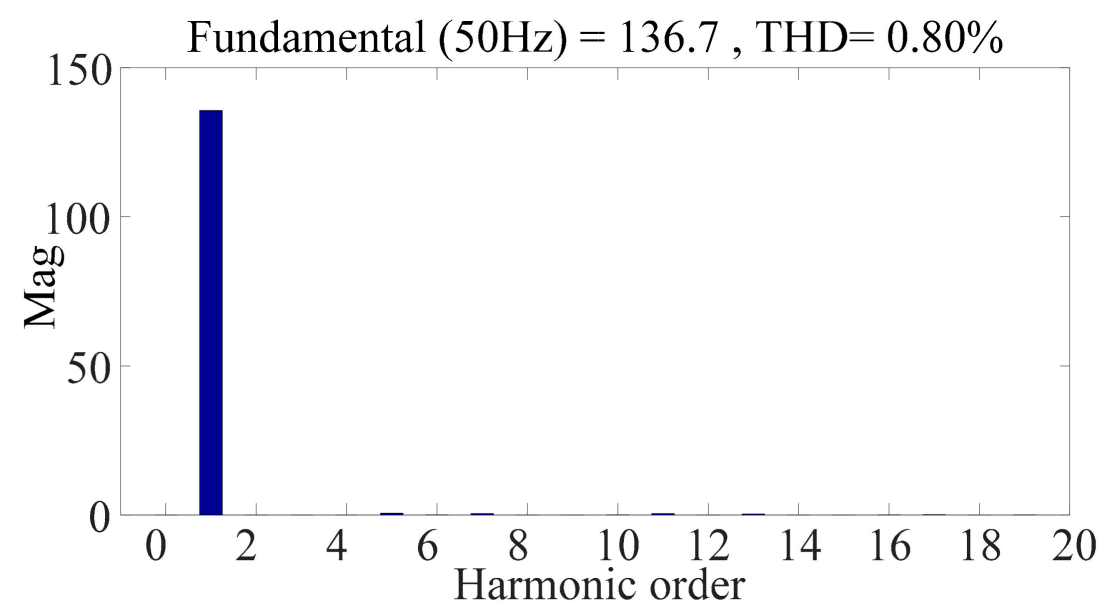

(e)

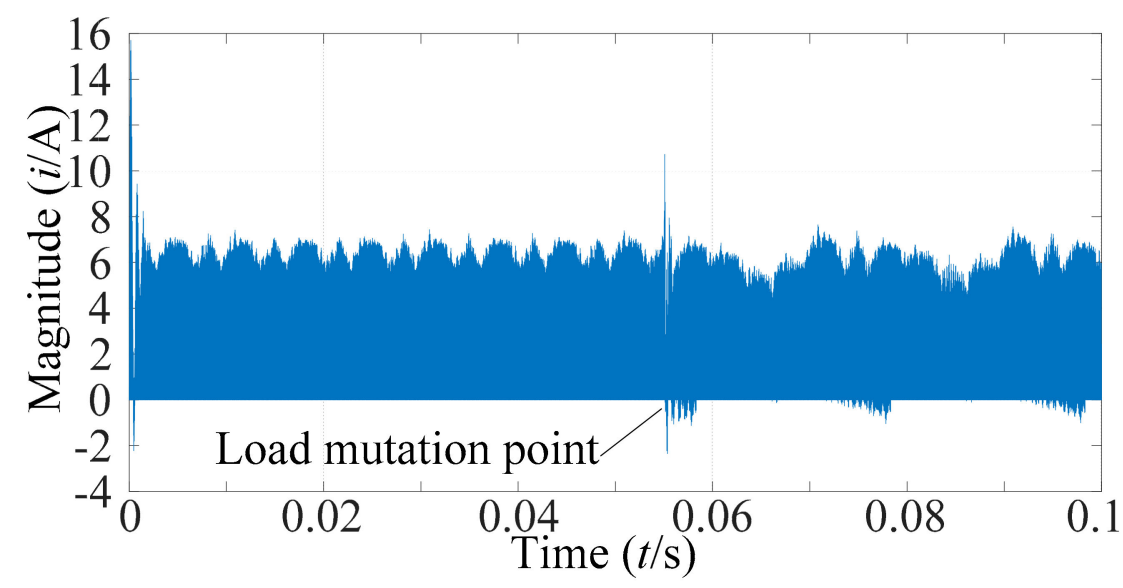

(f)

Figure 9. (a) Three-phase output voltage waveform; (b) three-phase output current waveform; (c) neutral line current waveform; (d) harmonic analysis of phase A voltage at load mutation; (e) harmonic analysis of phase A voltage after load mutation; and (f) current waveform flowing through $U_{\mathrm{dc}}$. 


\subsection{Nonlinear Load}

A benchmark nonlinear load is formulated in IEC standard, and this nonlinear load circuit is shown in Figure 10. We use this benchmark nonlinear load to test the capability of matrix converter with nonlinear load. Figure 11 shows the simulation results under nonlinear load conditions. The load conditions are: Phase A uses this benchmark nonlinear load, capacitance is $1000 \mu \mathrm{F}$, resistance is $50 \Omega$, both B-phase and C-phase resistance are $15 \Omega$. Figure 11a shows the three-phase output voltage waveform, and Figure $11 \mathrm{~b}, \mathrm{c}$ show the current and neutral current waveform. The cusp current waveform in the three-phase output current waveform diagram is the A-phase output current. It can be seen from the figure that the A-phase output current waveform tends to be stable in a short time after the simulation starts, the waveform is no longer changed. It can be seen from Figure 11d that the phase A output voltage has only a small number of low-order harmonics, the total harmonic distortion rate is $2.59 \%$, fundamental amplitude is 136.4. It can be seen from these waveforms that the distortion and imbalance of the output voltage are very small even when a high-power non-linear load is attached. The waveform of current flowing through $U_{\mathrm{dc}}$ under nonlinear load is shown in Figure 11e.

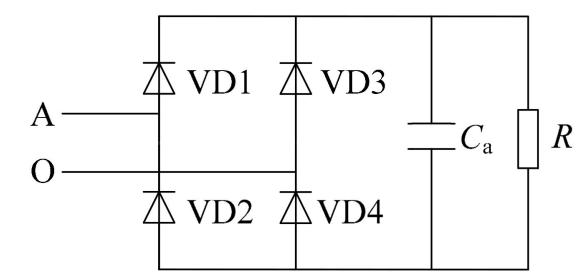

Figure 10. Nonlinear load circuit.

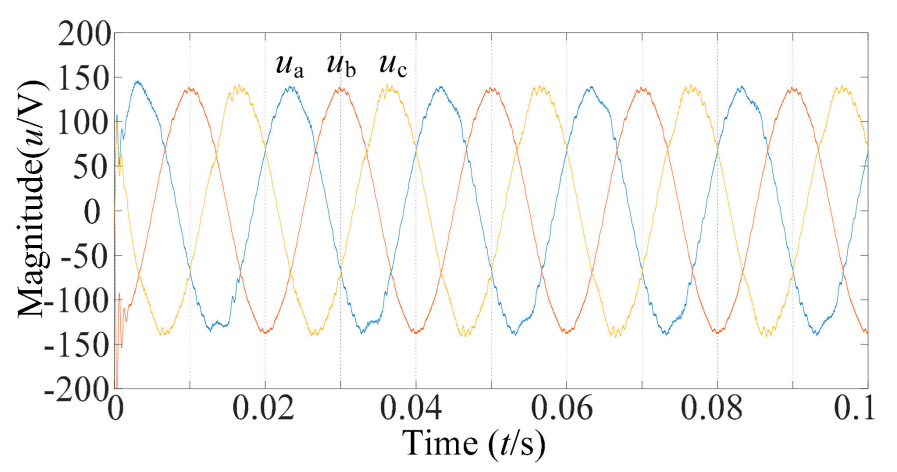

(a)

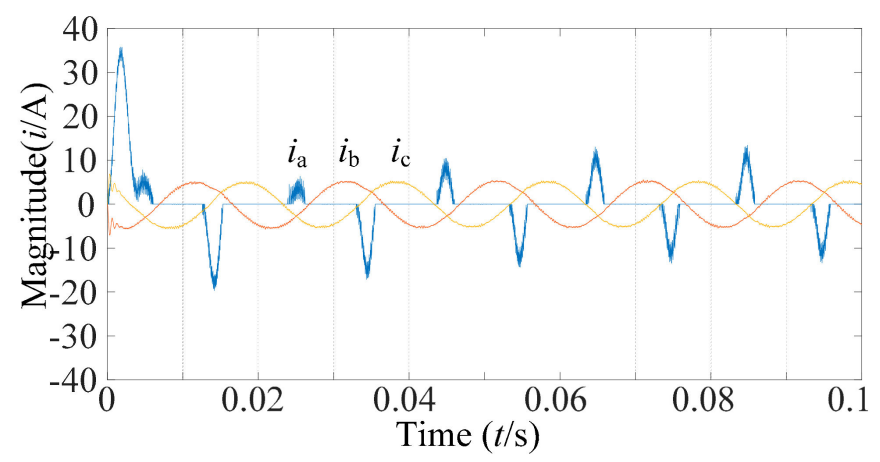

(b)

Figure 11. Cont. 


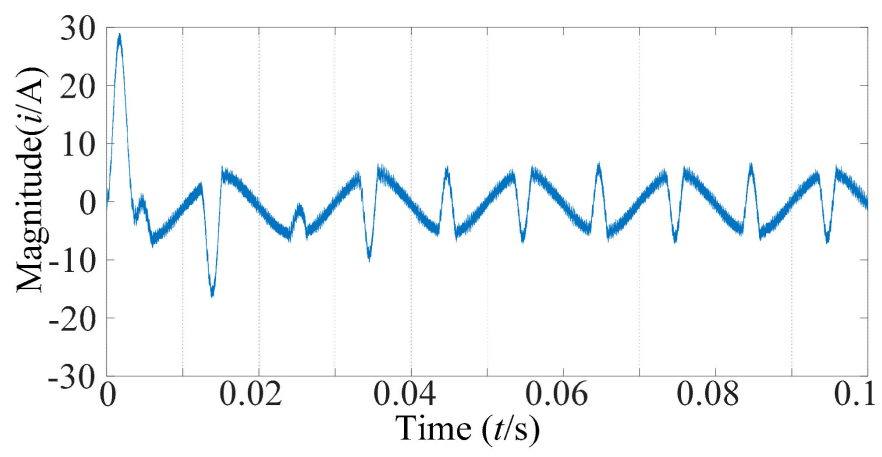

(c)

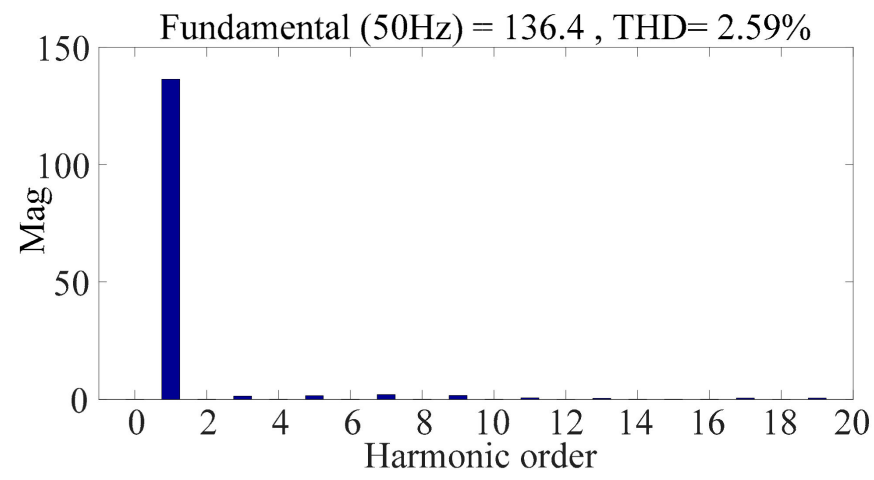

(d)

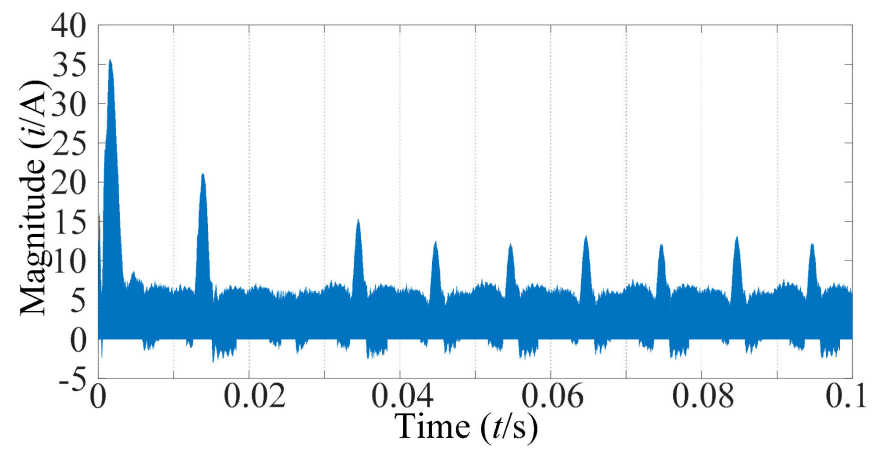

(e)

Figure 11. (a) Three-phase output voltage waveform; (b) three-phase output current waveform; (c) neutral line current waveform; (d) phase A voltage harmonic analysis; and (e) current waveform flowing through $U_{\mathrm{dc}}$.

It can be seen from the simulation results of the converter with the above three unbalanced loads that the proposed control strategy enhances the ability of HFL three-phase four-leg MC to adjust the output balance voltage. A stable three-phase symmetrical sine wave can still be output when the load fluctuates. It can effectively reduce the harmonic distortion rate, and the system has a strong load carrying capacity.

\section{Conclusions}

From the above analysis and simulation results, it can be proved that the combination of HPWM modulation and compensation modulation proposed in the HFLMC topology has the ability to withstand unbalanced loads perfectly. In the control strategy, the safe commutation of the bidirectional switch can be realized without other auxiliary detection circuits, which simplifies the system complexity, 
reducing the control cost. At the same time, the control idea of integrated current is adopted to change the problem that the previous HFL $3 \times 4 \mathrm{MC}$ control strategy cannot eliminate the interference when the load fluctuates, which shortens the adjustment response time of the system during load switching, reduces the THD. In safe operation, the commutation process is a one-step adaptive commutation that is naturally accompanied by HPWM control, the electrical isolation of the high frequency transformer structure ensures the safety of the inverter and human body. In terms of overall machine efficiency, the fourth bridge leg compatible control idea improves energy utilization while reducing system losses. In addition, the topology is compact and reliable, reducing the size and weight of the system. The method is simple and efficient, reducing the complicated calculations in previous control strategies. Therefore, the proposed control strategy, with many advantages, is expected to provide a useful reference for the practical application of the HFL three-phase four-leg MC.

Author Contributions: R.W. and F.W. conceived and designed the study. F.W. and H.P. performed the simulation research. F.W. and S.L. wrote the paper. R.W., F.W. and S.L. reviewed and edited the manuscript. All authors read and approved the manuscript. All authors have read and agreed to the published version of the manuscript.

Funding: This research is funded by National Key R and D Program of China under grant number 2017 YFB0903300.

Acknowledgments: Thanks to the lab partners for their simulation support and guidance.

Conflicts of Interest: The authors declare no conflict of interest.

\section{Appendix A}

Table A1. The definition of symbols in the paper.

\begin{tabular}{|c|c|}
\hline Symbols & Definition \\
\hline$u_{\mathrm{a}}$ & Phase A bridge leg terminal voltage \\
\hline$u_{\mathrm{b}}$ & Phase B bridge leg terminal voltage \\
\hline$u_{\mathrm{c}}$ & Phase $\mathrm{C}$ bridge leg terminal voltage \\
\hline$u_{\mathrm{n}}$ & Phase $\mathrm{N}$ bridge leg terminal voltage \\
\hline$i_{\mathrm{a}}$ & Phase A filter inductor current \\
\hline$i_{\mathrm{b}}$ & Phase B filter inductor current \\
\hline$i_{\mathrm{c}}$ & Phase $C$ filter inductor current \\
\hline$i_{\mathrm{n}}$ & Phase $\mathrm{N}$ filter inductor current \\
\hline$u_{\mathrm{AO}}$ & Phase A output voltage of the matrix converter \\
\hline$u_{\mathrm{BO}}$ & Phase B output voltage of the matrix converter \\
\hline$u_{\mathrm{CO}}$ & Phase $C$ output voltage of the matrix converter \\
\hline$U_{\mathrm{dc}}$ & $\begin{array}{l}\text { Input DC voltage of high-frequency link } \\
\text { three-phase four-leg matrix converter }\end{array}$ \\
\hline$U_{\mathrm{d}}$ & Input voltage of ordinary three-phase four-leg inverter \\
\hline$M(t)$ & Function of time \\
\hline$\theta$ & Phase angle \\
\hline$\omega$ & Angular velocity \\
\hline$L$ & Three-phase filter inductor \\
\hline$L_{\mathrm{n}}$ & Neutral line inductor \\
\hline C & Filter capacitor \\
\hline$k$ & Dynamic response adjustment factor \\
\hline $\mathrm{T}$ & high frequency transformer \\
\hline$u_{\mathrm{ca}}$ & sawtooth wave \\
\hline$u_{\mathrm{sa}}$ & sinusoidal modulation wave \\
\hline$u_{\mathrm{SPWM}}$ & Positive SPWM pulse \\
\hline $\bar{u}_{\mathrm{SPWM}}$ & Negative SPWM pulse \\
\hline$u_{1}$ & Positive high frequency square wave \\
\hline$u_{2}$ & Negative high frequency square wave \\
\hline$u_{\text {Skia }}$ & Four driving signals of phase A bridge leg \\
\hline VD & Diode in nonlinear circuits \\
\hline$C_{a}$ & Capacitor in nonlinear circuits \\
\hline
\end{tabular}




\section{Appendix B}

Table A2. The definition of acronyms in the paper.

\begin{tabular}{cl}
\hline Acronyms & \\
\hline HPWM & Hybrid pulse width modulation \\
HFL & High-frequency link \\
MC & Matrix converter \\
$3 \times 4$ MC & Three-phase four-leg matrix converter \\
HFLMC & High-frequency link matrix converter \\
3D-SVPWM & Three-dimensional space vector \\
$3 \times 3$ MC & Pulse width modulation \\
DC & Direct current \\
AC & Alternating current \\
HFAC & High-frequency alternating current \\
LFAC & Low-frequency alternating current \\
IGBT & Insulated gate bipolar transistor \\
SPWM & Sinusoidal pulse width modulation \\
THD & Total harmonic distortion \\
IEC & International Electro-Technical Commission \\
\hline
\end{tabular}

\section{References}

1. Gan, L.; Wu, Z.; Zeng, Y. Distributed power generation based asymmetric voltage regulator simulation. Power Syst. Prot. Control. 2009, 37, 35-39.

2. Noshahr, J.B.; Bagheri, M.; Kermani, M. The Estimation of the Influence of Each Harmonic Component in Load Unbalance of Distribution Transformers in Harmonic Loading Condition. In Proceedings of the 2019 IEEE International Conference on Environment and Electrical Engineering and 2019 IEEE Industrial and Commercial Power Systems Europe (EEEIC/I\&CPS Europe), Genova, Italy, 10-14 June 2019.

3. Zhang, R.; Boroyevich, D.; Prasad, H.; Mao, H.; Lee, F.C.; Dubovsky, S. A three-phase inverter with a neutral leg with space vector modulation. In Proceedings of the APEC 97-Applied Power Electronics Conference, Vancouver, BC, Canada, 24-25 November 1977; pp. 857-863.

4. Xing, X.; Sun, C.; Chen, J. Error Research of Retrieving Electric Power Due to Voltage Loss in Three-phase Four-wire Watt-hour Meter. J. Northeast Electr. Power Univ. 2018, 38, 1-7.

5. Shen, D.; Lehn, P.W. Fixed-frequency spacevector-modulation control for three-phase four-leg active power filters. IEE Proc.-Electr. Power Appl. 2002, 149, 268-274. [CrossRef]

6. Li, Y.W.; Vilathgamuwa, D.M.; Loh, P.C. Micro-grid power quality enhancement using a three-phase four-wire grid-interfacing compensator. IEEE Trans. Ind. Appl. 2005, 41, 1707-1719. [CrossRef]

7. Kumar, P.S. Design of high frequency power transformer for switched mode power supplies. In Proceedings of the 2016 International Conference on Emerging Trends in Engineering, Technology and Science (ICETETS 2016), Pudukkottai, India, 24-26 February 2016.

8. Hong, F.; Ji, B.; Wu, Y. Single-Stage Variable Turns Ratio High-Frequency Link Grid-Connected Inverter. IEEE Trans. Power Electron. 2018, 34, 7629-7636. [CrossRef]

9. Hirota, T.; Inomata, K.; Yoshimi, D.; Higuchi, M. Nine Switches Matrix Converter Using Bi-directional GaN Device. In Proceedings of the 2018 International Power Electronics Conference (IPEC-Niigata 2018 -ECCE Asia), Niigata, Japan, 20-24 May 2018.

10. Shinde, P.B.; Date, T.N. Pulse width modulation control of 3 phase AC-AC matrix converter. In Proceedings of the 2017 International Conference on Computing Methodologies and Communication (ICCMC), Erode, India, 18-19 July 2017; IEEE: Piscataway, NJ, USA, 2017.

11. Ammar, A.; Kanaan, H.Y.; Hamouda, M.; Al-Haddad, K. Review of Indirect Matrix Converter Topologies with Uniform Inputs versus Multi-Various Outputs. In Proceedings of the 2018 4th International Conference on Renewable Energies for Developing Countries (REDEC), Beirut, Lebanon, 1-2 November 2018. 
12. Yan, Z.; Li, R.; Xu, S. Modeling and control of high frequency link three-phase four-leg matrix converter. In Proceedings of the IECON 2013-39th Annual Conference of the IEEE Industrial Electronics Society, Vienna, Austria, 10-13 November 2013.

13. Yan, Z.; Bai, H.; Zhang, Z. Leg control strategy of high frequency link three-phase four-leg matrix inverter. In Proceedings of the 2016 IEEE 8th International Power Electronics and Motion Control Conference (IPEMC-ECCE Asia), Hefei, China, 22-26 May 2016.

14. Aijuan, J.; Hangtian, L.; Shaolong, L. A New High-Frequency AC Link Three-Phase Four-Wire Power Electronic Transformer. In Proceedings of the 2006 1ST IEEE Conference on Industrial Electronics and Applications, Singapore, 24-26 May 2006; IEEE: Piscataway, NJ, USA, 2006.

15. Ai, T.H.; Chen, J.F.; Liang, T.J. A random switching method for HPWM full-bridge inverter. IEEE Trans. Ind. Electron. 2002, 49, 595-597.

16. Panda, R.; Tripathi, R.K. A symmetrical hybrid sine PWM switching technique for full bridge inverters. In Proceedings of the 2006 India International Conference on Power Electronics, Chennai, India, 19-21 December 2006.

17. Chen, Y.; Qian, L.; Zhu, Z.; Yu, M. AC-AC Converter With the Z-Source and High Frequency link. Trans. China Electrotech. Soc. 2011, 26, 88-94.

18. Ansal, V.; Parthiban, P.; Ravikumar, K. Performance study of high frequency link AC-AC converter. In Proceedings of the International Conference on Advances in Energy Conversion Technologies, Manipal, India, 23-25 January 2014.

19. Kobravi, K.; Iravani, R.; Kojori, H.A. Three-Leg/Four-Leg Matrix Converter Generalized Modulation Strategy-Part I: A New Formulation. IEEE Trans. Ind. Electron. 2013, 60, 848-859. [CrossRef]

20. Changchun, Y.; Hao, T.; Yongsheng, W. Modulation strategy of single-phase high-frequency chain matrix converter. Power Electron. 2017, 2, 7-9.

21. Çimen, H.; Çetinkaya, N. Mitigation of Voltage Unbalance in Microgrids using Thermostatically Controlled Loads. In Proceedings of the 2018 2nd International Symposium on Multidisciplinary Studies and Innovative Technologies (ISMSIT), Ankara, Turkey, 19-21 October 2018.

22. Yan, Z.; Zhang, Z.; Li, J.; Xu, S. The Uni-Polarity Phase-Shifted Modulation Strategy for Single-Phase High-Frequency Link Inverter Based on De-Re-Coupling Idea and Dead Time Optimization. Trans. China Electrotech. Soc. 2018, 33, 1337-1346. [CrossRef]

23. Yan, Z.; Jia, M.; Zhang, C.; Wu, W. An Integration SPWM Strategy for High Frequency Link Matrix Converter with Adaptive Commutation in One Step Based on De-Re-coupling Idea. IEEE Trans. Ind. Electron. 2012, 59, 116-128. [CrossRef]

(C) 2019 by the authors. Licensee MDPI, Basel, Switzerland. This article is an open access article distributed under the terms and conditions of the Creative Commons Attribution (CC BY) license (http://creativecommons.org/licenses/by/4.0/). 